\title{
PEDOGÊNESE EM UMA SEQÜÊNCIA LATOSSOLO-PODZÓLICO NA BORDA DE UM PLATÔ NA DEPRESSÃO PERIFÉRICA PAULISTA ${ }^{(1)}$
}

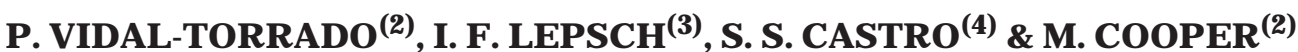

\begin{abstract}
RESUMO
Estudou-se uma seqüência de solos (Latossolo Vermel ho-E scuro álico textura muito argi losa $\rightarrow$ Podzólico Vermelho-E scuro distrófico textura argilosa/muito argilosa $\rightarrow$ Podzólico Vermelho-Amarelo eutrófico abrupto textura média/ argi losa), situados na borda de um platô, que representa a superfície mais antiga e dominante da paisagem regional e de boa parte do médio/baixo Vale do río Piracicaba, em Piracicaba (SP). Foram amostrados e descritos morfologicamente sete perfis de solos em trincheiras nos diferentes segmentos da vertente (topo, ombro, meia encosta e sopé). A confi guração lateral dos horizontes foi observada por meio de tradagens. Análises mi neralógicas, químicas e granulométricas foram feitas em amostras selecionadas dos horizontes. Nas amostras indefor madas dos horizontes e das transições entre estes, foram feitas a descrição e a análise micromorfológica para apoiar a interpretação da pedogênese. Os Latossolos muito argilosos do topo plano foram interpretados como formados a partir de um sedi mento argi loso neocenozóico que recobriu o platô, e os Podzólicos como resultantes de transformação pedológica lateral dos Latossolos com contribuição de siltitos da formação Tatuí (Ptt). A gênese dos microagregados dos Latossolos do topo é complexa, mas dois processos ficaram mais evidentes: o da microestruturação geoquímica e o da zoogenética. A transição lateral Bw-Bt foi atribuída ao adensamento em subsuperfície do manto latossólico, em conseqüência do rebai xamento e convexização da superfície topográfica origi nal durante o Quaternário e da influência crescente para jusante da ação mecânica do fluxo lateral de água. Posteriormente, mecanismos de argiluviação e de degradação de argilas por hidromorfismo temporário no topo do Bt completam a transformação do Bw em Bt e deste em E, respectivamente.
\end{abstract}

Termos de indexação: microagregados, adensamento de agregados, degradação do horizonte Bt, relações solo-pai sagem, micromorfologia.

(1) Trabalho apresentado no XXV Congresso Brasileiro de Ciência do Solo, Viçosa (MG), 1995. Parte da Tese de Doutorado apresentada pelo primeiro autor à ESALQ/USP. Projeto financiado pela FAPESP. Recebido para publicação em setembro de 1998 e aprovado em agosto de 1999.

(2) Professor do Departamento de Ciência do Solo, Escola Superior de Agricultura "Luiz de Queiroz", Universidade de São Paulo ESALQ/USP. Caixa Postal 09, CEP 13418-900 Piracicaba (SP). E-mail: pablo@carpa.ciagri.usp.br e mcooper@carpa.ciagri.usp.

(3) Professor do Departamento de Agronomia da Universidade Federal de Uberlândia. Caixa Postal 593, CEP 38400-902 U berlândia (MG).E-mail:Igo@ufu.br.

(4) Professor do Instituto de Estudos Sócio-Ambientais, UniversidadeF ederal de Goiás, Caixa Postal 131, Campus II. CEP $74001-970$ Goiânia (GO). E-mail: selma@iesa.ufg.br. 


\title{
SUMMARY: PEDOGENESIS OF AN OXISOL-ULTISOL-ALFISOL SEQUENCE ON THE BORDER OF A PLATEAU AT THE PAULISTA PERIPHERICAL DEPRESSION IN BRAZIL
}

\begin{abstract}
A soil sequence (Oxisol $\rightarrow$ Ultisol $\rightarrow$ Alfisol) was studied on the border of a plateau, which is the ol dest regional surfacenear the Piracicaba river valley (southeastern Brazil). Seven pits were identified, sampled and morphologically described under the different segments of thesequence(end of summit, shoulder, backsl opeand footsl ope). A bi-dimensional sketch of the soil horizons was drawn. Undeformed soil samples were taken for micromorphol ogical studies, and mi neralogical, chemical and granul ometric analyses were performed. The very clayey Oxisols of the flat summit are devel oped on a neo-cenozoic cover and theUltisols resulted from a lateral pedologic L atosol transformation gradually receiving at theend of the backsl opea contribution from fresh siltites (Tatuí formation, Permian). The genesis of thetop Oxisol mi croaggregates is complex, but two processes becameevident: the geochemical microstructure ant the zoogenetics. The Bw $\rightarrow$ Bt transition was attributed to thesubsurfacedensification of the mi croaggregates dueto thelevel ling and convexity of the original surface and to the lateral water flow's growing influence downstream. Further mechanisms of argilluviation and clay destruction of the Bt horizon top by temporary hydromorphism will complete the transformation of Bw into Bt and of the latter into $E$, respectively.
\end{abstract}

Index terms: microaggregates, natural aggregatedensification, argillichorizon degradation, soil geomorphology, soil micromorphology.

\section{NTRODUÇÃO}

Morfologicamente os Latossolos são peculiares por apresentarem horizonte $\mathrm{B}$, onde a maior parte do plasma está contido em agregados granulares muito pequenos, também denominados microagregados. A gênese desses microagregados tem sido objeto de vários estudos que, em geral, admitem a possibilidade de origem diversa (Stoops, 1983). Em trabalho de revisão sobre a micromorfologia de oxissolos, Stoops \& Buol (1985) distinguem cinco tipos de microagregados com pedogênese distinta: estruturais (ou de trama) (Beaudou et al., 1972; Muller, 1977), zoogenéticos (Eschenbrenner, 1986), reliquiais (Stoops, 1967), de origem geoquímica (Chauvel et al., 1978) e complexos (Muller, 1977).

A formação do horizonte B textural (Camargo et al., 1987) ou horizonte argílico (EUA, 1975), entretanto, ainda é alvo de discussões que não permitem uma compreensão clara, pois, na maior parte das vezes, há uma associação de processos, o que émais comum na natureza. Fedoroff \& E swaran (1985) apresentaram uma lista de possi bilidades ao estudar micromorfologicamente as argilas dos horizontes Bt.

Os processos considerados mais importantes e que levam à formação deste horizonte e do conseqüente gradientetextural são, resumidamente: a argiluviação, mais conheci do e aceito pela maioria dos autores, resultante da migração das argilas da camada superficial; a ferrólise, mecanismo de destruição das argilas dos horizontes superficiais por hidromorfismotemporário, que podeser acompanhado da argiluviação; o adensamento, menos conhecido que os dois processos citados, resultante de deformações plásticas, causado por ciclos de umedecimentoe secamento, freqüentementeassociado à argiluviação, além de outros menos conhecidos: a herança litológica (litodependência) e o coluvionamento.

Moniz (1996), em revisão sobre esse assunto, reafirma sua posição (Moniz \& Buol, 1982), admitindo o adensamento como o principal processo deformação do horizonte Bt, ainda que a argiluviação também possa ocorrer. Para el e a argiluviação atua de forma secundária ou apenas coadjuvante. Há, no entanto, autores que admitem até mesmo uma origem compl exa para a gênese dos Bt, quando um ou mais processos se interagem.

A transição lateral de Latossol os para Podzólicos de montante para jusante nas vertentes é uma das mais freqüentes na paisagem tropical. No Brasil, diversos trabalhos abordaram esta questão, como os deL epsch \& Buol (1976); Lepsch et al. (1977); Queiroz Neto et al . (1980); Moniz \& Buol (1982); Castro(1989); Miklós (1992); Vidal-Torrado \& Lepsch (1993). 
O quesedestaca, noentanto, éocomponenteadicional e da maior importância segundo os autores, que éa instal ação de fluxos hídricos laterais, em decorrência de novas condições hidrológicas. Estas seriam produzidas pelo rebaixamento do relevo em conseqüência do aprofundamento do nível de base, pelo menos desde que se instalaram os climas tropicais úmi dos com estação seca definida, durante - Quaternário. Apenas uma exceção caberia, queéa do truncamento erosivo dos Latossolos do topo, com subseqüente exposição do substrato que evoluiria para Bt.

Na Depressão Periférica Paulista, ocorre uma dominância de Latossol os nos topos planos eamplos do rel evo de col inas da Zona do MédioTietê, domínio onde se insere a região de Piracicaba. A superfície geomórfica correl ata a esses topos, situados em cotas entre 600 e $700 \mathrm{~m}$ acima do nível do mar, foi identificada por diversos geomorfól ogos como sendo parte de um grande pediplano que se estabeleceu ao redor de 1 a 1,5 milhão de anos atrás e recebeu o nome de superfície Rio Claro (Penteado, 1968).

$\mathrm{N}$ as bordas dos remanescentes desse pediplano, os L atossolos transicionam para sol os com B textural. Essa transição deve ser resultado da instalação de uma nova hidrologia e da exposição de materiais geológi cos mais frescos, resultando numa complexa pedogênese, envolvendo, provavelmente, boa parte da dinâmica descrita anteriormente. Buscando esclarecer tal pedogênese, estudou-se uma seqüência Latossolo Vermelho-Escuro álico textura muito argilosa $\rightarrow$ Podzólico Vermelho-E scuro álico ou distrófico textura argilosa/muito argilosa $\rightarrow$ Podzólico Vermelho-Amarelo eutrófico abrupto textura média/argilosa.

\section{MATE RIAL E MÉTODOS}

A área estudada situa-se no limite entre os municípios de Piracicaba e Santa Bárbara d'Oeste, no centro-leste do estado de São Paulo, entre as latitudes $22^{\circ} 42^{\prime}$ e $23^{\circ} 45^{\prime} \mathrm{S}$ e as longitudes $47^{\circ} 30^{\prime} \mathrm{e}$ 47032' W. Geomorfologicamente, está situada na Zona do Médio Tietê, na província da Depressão Periférica Paulista (Almeida, 1964), às margens do rio Piracicaba. O relevo local é formado por platôs dissecados, normal mente com escarpas nas bordas, seguidos de vales com rel evo suave ondulado.

A litologia do local é constituída principalmente por siltitos permianos, com conteúdo variável de carbonatos, da formação Tatuí (Ptt), membro superior do GrupoTubarão(IPT, 1981). A vegetação original, floresta mesófila semidecídua, está presente em pequenos remanescentes localizados nas escarpas. O uso atual da terra é com plantio de canade-açúcar. O clima da região, segundo a classificação deKöppen, é do tipo Cwa, istoé, mesotérmicoúmido subtropical de inverno seco (Comissão..., 1960). As médias anuais de temperatura e a precipitação pluviométrica, obtidas de uma série de dados de 81 anos fornecida pelo Departamento de Física e Agrometeorelogia da ESALQ/USP, são de $21,5^{\circ} \mathrm{C}$ e $1.270 \mathrm{~mm}$, respectivamente. A média de temperatura do mês mais frio é de $17,4^{\circ} \mathrm{C}$ e do mês mais quente $24,6^{\circ} \mathrm{C}$. O regime térmico dos solos é hipertérmico (Oliveira et al., 1976).

O detalhamento maior da geologia e da geomorfologia da área foi descrito em trabalho complementar (Vidal-Torrado et al., 1999). A seqüência estudada local iza-sena partemais elevada da paisagem regional, sendo constituída por um topo quase plano, seguido de um ombro, meia encosta e um sopé que grada para uma escarpa, que, por sua vez, está ligada às partes mais baixas do vale (Figura 1). Como se procura compreender a pedogênese e as alterações laterais dos Latossolos do topo, a seqüência foi interrompida no primeiro sopé, limitando-se, assim, à borda do platô.

Sete perfis de sol os foram descritos e amostrados em trincheiras ao longo da seqüência. N os sol os mais profundos, a seqüência vertical de horizontes foi avaliada por meio de tradagens profundas e de descrições morfol ógicas e col etas feitas num poço em escavação de $10 \mathrm{~m}$ de profundidade na posição mais el evada da seqüência (Perfil P1). Após as descrições morfológicas dos perfis, foram col etadas amostras deformadas de cada horizonte para análise química e granulométrica de rotina. Em horizontes e em transições entre horizontes selecionados dos perfis, coletaram-se amostras indeformadas e orientadas para a análise micromorfológica. Também foi elaborada uma figura bidimensional da geometria lateral dos horizontes, seguindo os procedimentos de campo recomendados por Boulet (1988).

A granulometria foi determinada, utilizando-se hidróxido de sódio e hexametafosfato de sódio (Camargo et al., 1986) como dispersantes. Os teores de silte e argil a foram determinados pel o método do densímetro e a fração areia por peneiramento. As análises químicas foram feitas de acordo com Raij et al. (1987). Os solos foram classificados de acordo com Camargo et al. (1987).

As amostras indeformadas e orientadas foram impregnadas com resina de poliéster (Castro, 1985), a partir das quais foram confeccionadas seções del gadas para análise micromorfológica, utilizando os critérios estabelecidos por Brewer (1976), com adaptações para a descrição da trama do solo, segundo Stoops \& J ongerius (1975); Brewer \& Sleeman (1988). Para as fotomicrografias, empregouse um fotomicroscópio Zeiss.

Em amostras selecionadas do horizonte $\mathrm{B}$ dos sol os, foi determinada a composição mineralógica da fração argila. O preparo e os tratamentos das amostras seguiram ométodo deJ ackson (1969). A pós eliminação da matéria orgânica e dos óxidos de ferro, 
a fração argila ( $<2 \mu \mathrm{m}$ ) foi separada por sifonagem. Subamostras foram saturadas com $\mathrm{K}+$ ou com $\mathrm{Mg}^{2+}$ e foram irradiadas com raios- $X$ por meio de difratômetro Rigaku, com tubo de Cu e filtro de $\mathrm{Ni}$, no intervalo $2 \theta$ de 3 a $32^{\circ}$. As subamostras saturadas com $\mathrm{K}$ + foram irradiadas na temperatura ambiente após aquecimento a 350 e $550^{\circ} \mathrm{C}$. As saturadas com Mg2+foram irradiadas na temperatura ambienteem duas etapas, antes e depois de solvatação com etileno-glicol, respectivamente.

\section{RESULTADOSE DISCUSSÃO}

A seqüência estudada situa-se na passagem entre as duas superfícies mais antigas identificadas na área por Vidal-Torrado et al . (1999). A seqüência foi repartida em diversos segmentos, a saber: topo, ombro, meia encosta esopé. A partir do sopé, seguese uma escarpa que liga o platô ao vale dissecado pelo rio Piracicaba (Figura 1).

\section{Morfologia e classificação dos perfis}

A figura 1 representa a configuração lateral dos horizontes dos solos e seus respectivos atributos morfológicos estão indicados no quadro 1.
Os perfis locados no topo P1, P2, P3 e P4 foram classificados como Latossolo Vermelho-Escuro textura muito argilosa. Na profundidade de 80 a $100 \mathrm{~cm}$, inicia-se um horizonte B latossólico (Bw) muito espesso, com forte microagregação. Nesses quatro perfis, entre o horizonte Ap e o Bw, ocorre um horizonte BA com blocos subangulares com tamanho de 2 a $5 \mathrm{~cm}$, de consistência friável e cerosidade moderada e comum, concentrada principalmente nas paredes dos agregados. A atividade biológica é muito evidente tanto no horizonte $B$ como no horizonte BA, sendo comum a presença de crotovinas (preenchidas por material solto granular) e pedotúbulos.

A partir do ombro, o perfil $\mathrm{P} 5$ foi classificado como Podzól ico Vermelho-Escuro. A estrutura do horizonte B passa a apresentar agregados maiores, em forma deblocos subangulares e prismas detamanho entre 2 e $3 \mathrm{~cm}$, com grau forte de agregação, características essas de horizonte Bt. A cerosidade reveste preferencialmente as paredes verticais e oblíquas dos agregados, sendo descrita como forte e comum. Na profundidade de 120 a $140 \mathrm{~cm}$, aparecem seixos esparsos de quartzo e quartzito, com 1 a $2 \mathrm{~cm}$ de diâmetro, juntamente com nódulos argilosos de mesma dimensão. Também neste perfil a atividade biológica é bastante evidente, considerando as de

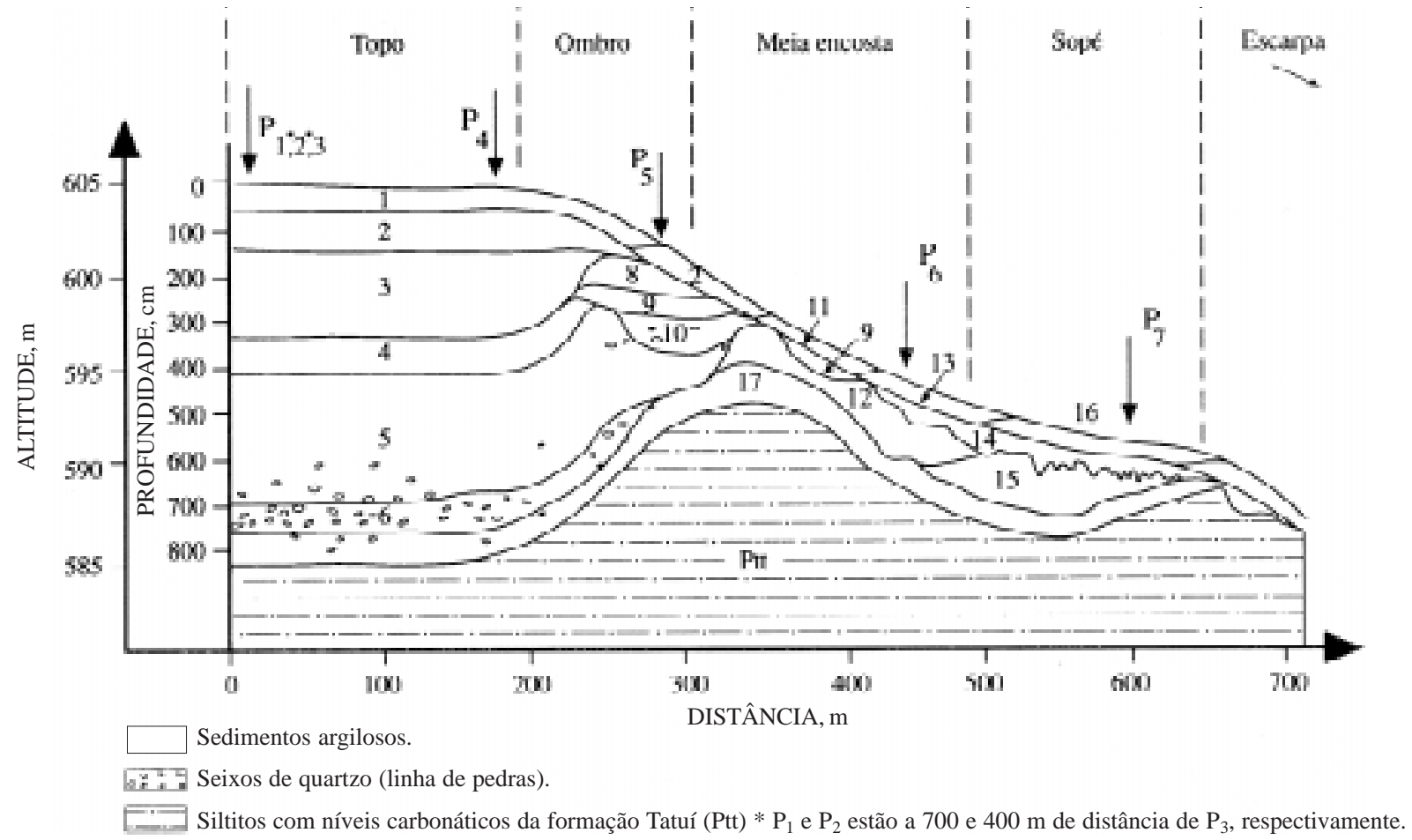

Figura 1. Perfil topográfico da seqüência estudada contendo: delimitação dos segmentos da vertente; posição dos perfis; configuração lateral dos horizontes, da linha de pedras e da rocha subjacente. 1,2,...17: horizontes do solo (Quadro 1). A transeção escolhida atravessa um remanescente de uma antiga superfície, que é a mais elevada e plana da região. Os perfis de 4 a 7 situam-se na borda do platô. 0 material inconsolidado neocenozóico coincide com o Latossolo (perfis 1 a 4). 
Quadro 1. Atributos morfológicos dos principais horizontes observados na figura 1

\begin{tabular}{|c|c|c|c|c|c|}
\hline $\begin{array}{l}\text { Número } \\
\text { (Figura 1) }\end{array}$ & Horizonte & Cor úmida & Textura & Estrutura do B & Observações \\
\hline 1 & Ap & $2,5 Y R 3 / 4$ & muito argilosa & & \\
\hline 2 & $A B, B A$ & $2,5 Y R 3 / 5$ & muito argilosa & subg. méd. mod. & \\
\hline 3 & Bw1 & $2,5 Y R 3 / 6$ & muito argilosa & gran. peq. fte. & Nódul os de argila comuns \\
\hline 4 & $\mathrm{Bw} 2$ & $2,5 Y R 4 / 8$ & muito argilosa & gran. peq. fte. & \\
\hline 5 & Bw3 & $2,5 Y R 4 / 7$ & muito argilosa & gran. peq. fte. & $\begin{array}{l}\text { Presença de agregados densos e } \\
\text { centimétricos }\end{array}$ \\
\hline 6 & $2 B C$ & $2,5 Y R 4 / 7$ & argila & & $\begin{array}{l}\text { Seixos de quartzo comuns e presença de } \\
\text { fragmentos de siltito alterado }\end{array}$ \\
\hline 7 & Ap & $5 Y R 4 / 6$ & argila arenosa & & \\
\hline 8 & Bt & $2,5 Y R 3 / 4$ & muito argilosa & subg. + pri. méd. fte. & Cerosidade forte e comum \\
\hline 9 & Bt & $2,5 Y R$ B,5/6 & muito argilosa & subg. + pri. méd. fte. & Cerosidade forte e comum \\
\hline 10 & $\mathrm{Bt}$ & $2,5 Y R \quad 4 / 6$ & muito argilosa & $\begin{array}{l}\text { subg. + pri. méd. } \\
\text { mod. ou fte. }\end{array}$ & $\begin{array}{l}\text { Cerosidade forte e comum ou moderada e } \\
\text { comum }\end{array}$ \\
\hline 11 & Ap & $7,5 Y R \quad 4 / 5$ & argila arenosa & & \\
\hline 12 & $\mathrm{Bt}$ & $2,5 Y R$ 5/8 & argila & subg. peq. mod. a fte. & Cerosidade forte abundante \\
\hline 13 & Ap & 10YR $4 / 4$ & franco-argilo arenosa & & \\
\hline 14 & E & 10YR 6/6 & franco arenoso & & $\begin{array}{l}\text { Topografia da transição do E para Bt é } \\
\text { irregular }\end{array}$ \\
\hline 15 & Btg & $5 Y R 5 / 6$ & muito argilosa & pri. peq a méd. fte. & $\begin{array}{l}\text { Mosqueados pequenos e muito pequenos } \\
\text { comuns (10YR } 6 / 6,5 Y R 5 / 8 \text { e } 5 Y \text { Y } 7 / 1) \text {. } \\
\text { Superfícies de compressão comuns na } \\
\text { parte inferior do horizonte }\end{array}$ \\
\hline 16 & Ap & 10YR $4 / 2$ & franco-arenosa & & \\
\hline 17 & $\mathrm{BC}$ ou $\mathrm{CR}$ & 5 a $10 Y R$ & argila a franco-argilosa & $\begin{array}{l}\text { variável, predominando } \\
\text { aspecto maciço }\end{array}$ & $\begin{array}{l}\text { Grau de alteração da rocha variável desde } \\
\text { pouco alterada ( } 2 C R \text { ou } C R \text { ) a apenas } \\
\text { pequenas pontuaçôes de alteritas }(B C)\end{array}$ \\
\hline
\end{tabular}

Abreviações: subg: subangular; pri: prismática; peq: pequena; méd: média; fte: forte; mod: moderado; gran: grande.

galerias biológicas, crotovinas e pedotúbulos observados principalmente no horizonte Bt.

O perfil P6 localiza-se na meia encosta. Trata-se também de Podzólico Vermelho-Escuro, com cerosidade muito evidenteno horizonteBt, formando revestimentos espessos (vistona lupa), em agregados de grau forte e conformação poliédrica (blocos subangulares, principalmente). Preenchimentos biológicos de até $1 \mathrm{~cm}$ de diâmetro (pedotúbulos) são nítidos e comuns até $100 \mathrm{~cm}$ de profundidade aproximadamente. Em comparação com o perfil anterior (P5), a textura do horizonte Bt é menos argilosa (550 g kg-1 no P6 contra $700 \mathrm{~g} \mathrm{~kg}^{-1}$ no P5) e a passagem do horizonte A para o Bt é abrupta.

O P7 é o último dos perfis da seqüência. Situa-se no sopé e difere bastante em sua morfologia e atributos químicos do demais perfis. Classificado como Podzólico Vermel ho-Amarelo, a cor do horizonte Bt deixa deter matizes 2,5YR e passa a 7,5YR, com cores brunas e presença de volumes bruno- esverdeados e bruno-ocre, numa estrutura com agregados prismáticos de 4 a $8 \mathrm{~cm}$ de tamanho, com grau forte de agregação. As faces dos agregados do Bt apresentam superfícies lisas e revestimentos contínuos. A transição de E para Bt éabrupta, com mudança textural também abrupta. A textura superficial é média e no Bt é argilosa tendendo a muito argilosa.

\section{Atributos químicos}

A saturação por bases (Quadro 2) aumenta gradativamente a partir da ruptura do declive do topo para o ombro, atingindo o val or máxi mo no sopé (P7). A passagem é de álico no topo (P1, P2, P3 eP4) para distrófico no ombro (P5) e, finalmente, eutrófico na meia encosta e sopé (P6 e P7).

Valores de CTC dos horizontes até $130 \mathrm{~cm}$ dos solos do topo (P1 a P4) são superiores aos dos Latossolos, passando a valores aceitáveis para esse grupamento a partir dessa profundidade (Quadro 2). 
Quadro 2. Atributos químicos e granulométricos dos solos

\begin{tabular}{|c|c|c|c|c|c|c|c|c|c|c|c|c|}
\hline \multirow{2}{*}{ Horizonte } & \multirow{2}{*}{ Profundidade } & \multicolumn{3}{|c|}{ Granulometria } & \multirow{2}{*}{$\begin{array}{c}\text { pH } \\
\mathrm{H}_{2} \mathrm{O}\end{array}$} & \multirow{2}{*}{ C } & \multirow{2}{*}{$\mathbf{A l}^{3+}$} & \multirow{2}{*}{$\mathbf{S}$} & \multirow{2}{*}{ СтC } & \multirow{2}{*}{$\mathbf{T}^{(\mathbf{1})}$} & \multirow{2}{*}{$\mathbf{m}$} & \multirow{2}{*}{$\mathbf{v}$} \\
\hline & & Areia & Silte & Argila & & & & & & & & \\
\hline & $\mathrm{cm}$ & $\underline{-}$ & $\mathrm{g} \mathrm{kg}^{-1}$ & - & & $\mathrm{g} \mathrm{kg}^{-1}$ & $\underline{-}$ & $-\mathrm{mm}$ & $\mathrm{kg}^{-1}$ & & $\longrightarrow$ & - \\
\hline \multicolumn{13}{|c|}{ P1 Latossolo Vermelho-Escuro álico A moderado textura muito argilosa } \\
\hline $\begin{array}{l}\text { Ap } \\
\text { AB } \\
\text { Bw1 } \\
\text { Bw2 } \\
\text { Bw3 } \\
\text { Bw4 } \\
\text { Bw5 } \\
\text { Bw6 } \\
\text { Bw7 } \\
\text { 2BC } \\
\text { 2C }\end{array}$ & $\begin{array}{c}00-25 \\
25-70 \\
105-130 \\
130-160 \\
160-200 \\
200-250 \\
250-400 \\
500-550 \\
600-700 \\
800-900 \\
1000-110\end{array}$ & $\begin{array}{l}250 \\
150 \\
180 \\
180 \\
180 \\
220 \\
253 \\
200 \\
310 \\
250 \\
140\end{array}$ & $\begin{array}{r}120 \\
70 \\
80 \\
60 \\
110 \\
100 \\
150 \\
240 \\
220 \\
260 \\
390\end{array}$ & $\begin{array}{l}630 \\
780 \\
740 \\
760 \\
710 \\
680 \\
600 \\
560 \\
470 \\
490 \\
470\end{array}$ & $\begin{array}{l}4,8 \\
4,6 \\
4,5 \\
4,8 \\
4,6 \\
5,4 \\
5,2 \\
4,8 \\
4,7 \\
4,7 \\
4,5\end{array}$ & $\begin{array}{r}24 \\
20 \\
16 \\
11 \\
10 \\
7 \\
7 \\
7 \\
7 \\
7 \\
6\end{array}$ & $\begin{array}{r}14 \\
26 \\
23 \\
13 \\
10 \\
2 \\
2 \\
10 \\
10 \\
27 \\
33\end{array}$ & $\begin{array}{r}35 \\
25 \\
12 \\
8 \\
4 \\
21 \\
23 \\
26 \\
18 \\
22 \\
5\end{array}$ & $\begin{array}{r}144 \\
191 \\
147 \\
72 \\
68 \\
49 \\
60 \\
68 \\
60 \\
110 \\
190\end{array}$ & $\begin{array}{r}57 \\
129 \\
101 \\
30 \\
32 \\
26 \\
48 \\
65 \\
61 \\
160 \\
347\end{array}$ & $\begin{array}{r}29 \\
51 \\
66 \\
62 \\
71 \\
9 \\
10 \\
28 \\
36 \\
55 \\
87\end{array}$ & $\begin{array}{r}24 \\
13 \\
8 \\
11 \\
6 \\
43 \\
42 \\
38 \\
30 \\
20 \\
3\end{array}$ \\
\hline \multicolumn{13}{|c|}{ P2 Latossolo Vermelho-Escuro câmbico álico A moderado textura muito argi losa } \\
\hline $\begin{array}{l}\text { Ap } \\
A B \\
B A \\
\text { Bw1 } \\
\text { Bw2 } \\
\text { Bw3 }\end{array}$ & $\begin{array}{c}00-30 \\
30-48 \\
48-102 \\
102-150 \\
150-200 \\
200-250\end{array}$ & $\begin{array}{l}200 \\
130 \\
130 \\
140 \\
160 \\
140\end{array}$ & $\begin{array}{r}130 \\
90 \\
70 \\
110 \\
110 \\
150\end{array}$ & $\begin{array}{l}670 \\
780 \\
800 \\
750 \\
730 \\
710\end{array}$ & $\begin{array}{l}4,8 \\
4,8 \\
4,5 \\
4,6 \\
4,7 \\
4,9\end{array}$ & $\begin{array}{r}24 \\
23 \\
20 \\
16 \\
9 \\
7\end{array}$ & $\begin{array}{r}17 \\
17 \\
26 \\
26 \\
6 \\
3\end{array}$ & $\begin{array}{l}36 \\
30 \\
18 \\
14 \\
30 \\
31\end{array}$ & $\begin{array}{r}145 \\
165 \\
203 \\
185 \\
72 \\
69\end{array}$ & $\begin{array}{r}55 \\
79 \\
141 \\
151 \\
43 \\
53\end{array}$ & $\begin{array}{r}32 \\
36 \\
59 \\
65 \\
17 \\
9\end{array}$ & $\begin{array}{r}25 \\
18 \\
9 \\
8 \\
42 \\
45\end{array}$ \\
\hline \multicolumn{13}{|c|}{ P3 Latossolo Vermelho-Escuro câmbico álico A moderado textura muito argi losa } \\
\hline $\begin{array}{l}\text { Ap } \\
\text { AB } \\
\text { BA } \\
\text { Bw1 } \\
\text { Bw2 } \\
\text { Bw3 } \\
\text { Bw4 }\end{array}$ & $\begin{array}{c}00-20 \\
20-52 \\
52-88 \\
88-117 \\
117-150 \\
150-200 \\
200-250\end{array}$ & $\begin{array}{r}180 \\
80 \\
90 \\
100 \\
130 \\
120 \\
160\end{array}$ & $\begin{array}{l}150 \\
100 \\
110 \\
100 \\
110 \\
190 \\
150\end{array}$ & $\begin{array}{l}670 \\
820 \\
800 \\
800 \\
760 \\
690 \\
690\end{array}$ & $\begin{array}{l}5,1 \\
4,7 \\
4,5 \\
4,5 \\
4,7 \\
4,7 \\
4,9\end{array}$ & $\begin{array}{r}26 \\
19 \\
16 \\
15 \\
12 \\
7 \\
7\end{array}$ & $\begin{array}{r}8 \\
21 \\
28 \\
24 \\
15 \\
6 \\
3\end{array}$ & $\begin{array}{r}35 \\
27 \\
14 \\
11 \\
8 \\
24 \\
29\end{array}$ & $\begin{array}{r}123 \\
177 \\
199 \\
177 \\
96 \\
66 \\
60\end{array}$ & $\begin{array}{r}9 \\
112 \\
159 \\
137 \\
55 \\
50 \\
41\end{array}$ & $\begin{array}{r}19 \\
44 \\
67 \\
69 \\
65 \\
20 \\
9\end{array}$ & $\begin{array}{r}28 \\
15 \\
7 \\
6 \\
8 \\
36 \\
48\end{array}$ \\
\hline \multicolumn{13}{|c|}{ P4 Latossolo Vermelho-E scuro câmbico álico A moderado textura muito argi losa } \\
\hline $\begin{array}{l}\text { Ap } \\
A B \\
B A \\
\text { Bw1 } \\
\text { Bw2 } \\
\text { Bw3 } \\
\text { Bw4 } \\
\text { Bw5 } \\
\text { Bw6 } \\
2 B C 1 \\
2 B C 2 \\
2 C\end{array}$ & $\begin{array}{c}00-20 \\
20-51 \\
51-94 \\
94-132 \\
132-150 \\
150-200 \\
200-250 \\
400-450 \\
600-650 \\
650-700 \\
750-800 \\
800-850\end{array}$ & $\begin{array}{r}270 \\
70 \\
180 \\
160 \\
180 \\
160 \\
200 \\
270 \\
190 \\
330 \\
240 \\
150\end{array}$ & $\begin{array}{r}130 \\
110 \\
80 \\
110 \\
130 \\
140 \\
110 \\
180 \\
260 \\
250 \\
230 \\
310\end{array}$ & $\begin{array}{l}600 \\
820 \\
740 \\
730 \\
690 \\
700 \\
690 \\
550 \\
550 \\
420 \\
530 \\
540\end{array}$ & $\begin{array}{l}5,2 \\
5,2 \\
4,5 \\
4,5 \\
4,6 \\
4,8 \\
4,9 \\
5,2 \\
5,1 \\
4,9 \\
4,7 \\
4,7\end{array}$ & $\begin{array}{r}31 \\
19 \\
18 \\
13 \\
10 \\
8 \\
7 \\
7 \\
6 \\
6 \\
7 \\
7\end{array}$ & $\begin{array}{r}6 \\
8 \\
8 \\
8 \\
8 \\
9 \\
6 \\
3 \\
9 \\
14 \\
20 \\
28\end{array}$ & $\begin{array}{r}49 \\
48 \\
14 \\
9 \\
9 \\
24 \\
30 \\
20 \\
23 \\
21 \\
29 \\
22\end{array}$ & $\begin{array}{r}129 \\
136 \\
219 \\
159 \\
89 \\
71 \\
68 \\
51 \\
65 \\
63 \\
76 \\
102\end{array}$ & $\begin{array}{r}- \\
62 \\
186 \\
138 \\
64 \\
50 \\
53 \\
35 \\
69 \\
86 \\
84 \\
131\end{array}$ & $\begin{array}{l}11 \\
14 \\
67 \\
76 \\
67 \\
27 \\
17 \\
13 \\
28 \\
40 \\
41 \\
56\end{array}$ & $\begin{array}{r}38 \\
35 \\
6 \\
6 \\
10 \\
34 \\
44 \\
39 \\
35 \\
33 \\
38 \\
22\end{array}$ \\
\hline \multicolumn{13}{|c|}{ P5 Latossolo Vermelho-Escuro distrófico Tb A moderado textura argi losa/muito argi losa } \\
\hline $\begin{array}{l}\text { Ap } \\
\text { Bt1 } \\
2 B t 2\end{array}$ & $\begin{array}{l}00-33 \\
33-70 \\
70-150\end{array}$ & $\begin{array}{l}410 \\
180 \\
180\end{array}$ & $\begin{array}{l}210 \\
130 \\
120\end{array}$ & $\begin{array}{l}380 \\
690 \\
700\end{array}$ & $\begin{array}{l}5,3 \\
5,4 \\
5,1\end{array}$ & $\begin{array}{r}15 \\
12 \\
9\end{array}$ & $\begin{array}{l}6 \\
4 \\
6\end{array}$ & $\begin{array}{l}25 \\
29 \\
20\end{array}$ & $\begin{array}{l}63 \\
67 \\
58\end{array}$ & $\begin{array}{r}- \\
19 \\
25\end{array}$ & $\begin{array}{l}19 \\
12 \\
23\end{array}$ & $\begin{array}{l}40 \\
43 \\
34\end{array}$ \\
\hline \multicolumn{13}{|c|}{ P6 Latossolo Vermelho-E scuro eutrófico Tb A moderado média/argilosa } \\
\hline $\begin{array}{l}\text { Ap/E } \\
\text { Bt1 } \\
\text { Bt2 } \\
\text { Bt3 }\end{array}$ & $\begin{array}{l}00-33 \\
33-77 \\
77-110 \\
110+\end{array}$ & $\begin{array}{l}480 \\
280 \\
270 \\
290\end{array}$ & $\begin{array}{l}160 \\
160 \\
180 \\
160\end{array}$ & $\begin{array}{l}360 \\
560 \\
550 \\
550\end{array}$ & $\begin{array}{l}5,6 \\
5,2 \\
5,4 \\
5,2\end{array}$ & $\begin{array}{r}14 \\
10 \\
7 \\
7\end{array}$ & $\begin{array}{l}3 \\
1 \\
3 \\
3\end{array}$ & $\begin{array}{l}29 \\
28 \\
24 \\
26\end{array}$ & $\begin{array}{l}51 \\
56 \\
49 \\
57\end{array}$ & $\begin{array}{r}- \\
20 \\
32 \\
46\end{array}$ & $\begin{array}{r}9 \\
3 \\
11 \\
10\end{array}$ & $\begin{array}{l}57 \\
50 \\
50 \\
46\end{array}$ \\
\hline \multicolumn{13}{|c|}{ P7 Latossolo Vermelho-Amarelo eutrófico Tb A moderado abrupto média/argi losa } \\
\hline $\begin{array}{l}\text { Ap } \\
\text { E } \\
\text { Bt1 } \\
\text { Btg1 } \\
\text { Btg2 }\end{array}$ & $\begin{array}{l}00-23 \\
23-32 \\
32-47 \\
47-75 \\
75-140\end{array}$ & $\begin{array}{r}490 \\
480 \\
350 \\
280 \\
80\end{array}$ & $\begin{array}{l}290 \\
300 \\
220 \\
180 \\
300\end{array}$ & $\begin{array}{l}220 \\
220 \\
430 \\
540 \\
620\end{array}$ & $\begin{array}{l}5,0 \\
4,9 \\
5,4 \\
5,2 \\
5,3\end{array}$ & $\begin{array}{r}16 \\
13 \\
11 \\
11 \\
8\end{array}$ & $\begin{array}{r}8 \\
6 \\
5 \\
7 \\
14\end{array}$ & $\begin{array}{l}21 \\
22 \\
54 \\
66 \\
48\end{array}$ & $\begin{array}{r}59 \\
60 \\
85 \\
108 \\
95\end{array}$ & $\begin{array}{r}- \\
7 \\
83 \\
108 \\
95\end{array}$ & $\begin{array}{r}28 \\
21 \\
8 \\
10 \\
23\end{array}$ & $\begin{array}{l}36 \\
37 \\
64 \\
61 \\
51\end{array}$ \\
\hline
\end{tabular}

(1) Valores em mmol $\mathrm{kg}^{-1}$ de argila, calculado pela expressão T $=1000$ (CTC - 4,5 C)/argila. 
O cál culo da CTC/100 g de argila com desconto para carbono (valor $\mathrm{T}$ ) demonstrou que os perfis $\mathrm{P} 2$, $\mathrm{P} 3 \mathrm{e}$ P4 devem ser classificados como Latossol os câmbicos (Quadro 2), uma vez que, na parte superior do horizonte $\mathrm{B}$ (BA e Bw1), os valores de T superam o limite de $130 \mathrm{mmol}_{\mathrm{C}} \mathrm{kg}^{-1}$ para B latossólico (Camargo et al., 1987).

Possível erroa considerar nestes cál culos éo valor de CTC imputado a cada $1 \%$ de $\mathrm{C}$, que é de $45 \mathrm{mmol}_{C} \mathrm{~kg}^{-1}$, eque poderia subestimar a participação dos colói des orgâni cos na CTC. Essas consi derações e a proximidade encontrada entre olimite admitido deT para oB latossól ico e os valores desse parâmetro nos horizontes BA e Bw1 de P2 a P4 (Quadro 2) colocam em caráter condicional a adjetivação "câmbico" nestes três perfis de Latossolo, uma vez que não reúnem outros atributos para assim serem classificados.

Os valores de CTC no horizonte Bt de P7 são o dobro do horizonte $B$ dos demais perfis da seqüência.

\section{Mineralogia da fração argila}

Os difratogramas da fração argila dos perfis localizados no topo mostraram mineralogia similar (Figura 2). São solos cauliníticos com presença de gibbsita e de vermiculita com hidroxi entre camadas ou, simplesmente, VHE (F ontes, 1990), esta última em menor proporção. A partir de $8 \mathrm{~m}$ de profundidade, na camada derocha alterada (siltitos do Ptt), atingida pela tradagem profunda realizada no perfil 4 , surge um picoao redor de $1,0 \mathrm{~nm}$ correspon-denteàs micas, além da caulinita e pouca gibbsita.

Além da contribuição na CTC pela matéria orgânica humificada, a hipótese sugerida para explicar os valores relativamente el evados de CTC nos horizontes $A, A B, B A$ e Bw1 dos Latossolos é a de que esteja havendo um acúmulo relativo de VHE nessas camadas mais próximas da superfície e, portanto, mais expostas à ação do intemperismo. Nas condições atuais, a VHE seria mais estável do quea caulinita (Karathanasis et al. 1983), acumulando-se
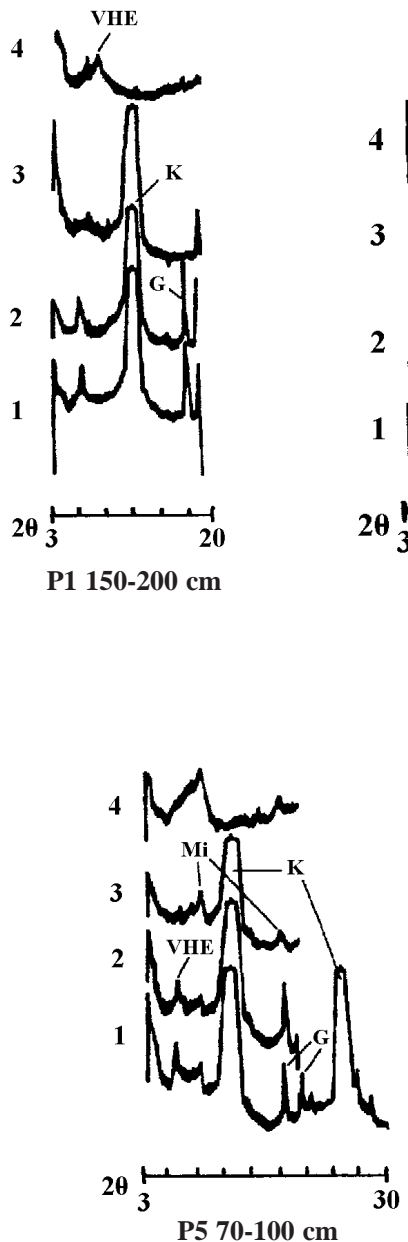

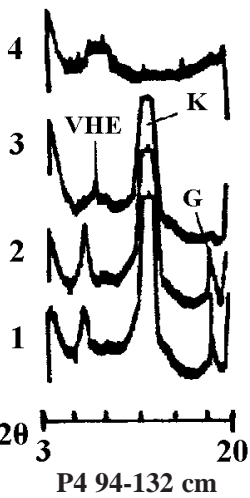

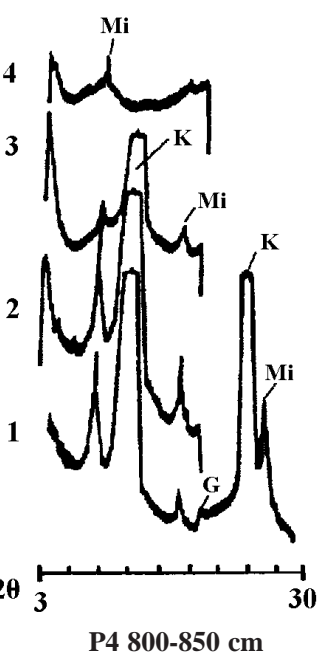
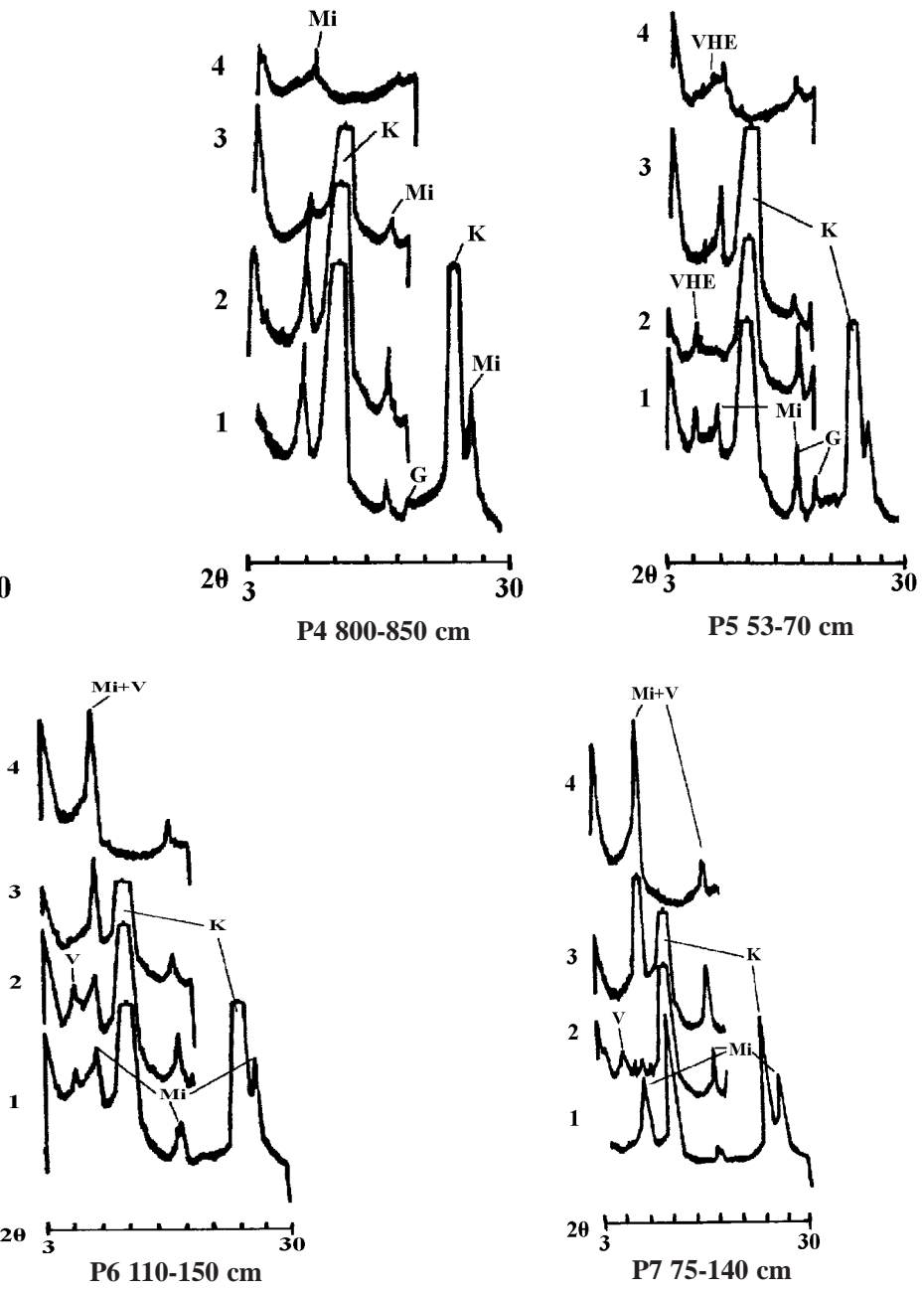

Figura 2. Difratogramas da fração argila dos perfis estudados. Tratamentos: (1) $\mathrm{K}^{+} 25^{\circ} \mathrm{C}$; (2) $\mathrm{Mg}^{2+} 25^{\circ} \mathrm{C}$, glicolada; (3) $\mathrm{K}^{+}, 350^{\circ} \mathrm{C}$; (4) $\mathrm{K}^{+} 550^{\circ} \mathrm{C}$. Mi: mica (ilita); V: vermiculita; VHE (vermiculita com hidróxi entrecamadas); K: caulinita; G: gibbsita. 
residualmente e aumentando a CTC. Embora se trate de uma aproximação sujeita a erros de estimativa da contribuição da matéria orgânica humificada, a CTC das argilas, descontada a participação da matéria orgânica (valor T) desses perfis (Quadro 2), corrobora tal hipótese e a tendência observada nos difratogramas, pois os val ores deT atéà profundidade de 120 a $150 \mathrm{~cm}$ são excessivos para solos essencialmente cauliníticos, sendo, no entanto, mais adequados à mineral ogia 1:1 com participação de VHE.

A partir do perfil 5, a mineralogia modifica-se ligeiramente, com menor participação de VHE e o surgimento de mica secundária no horizonteBt desse sol o. A ocorrência de mica aumenta gradativamente em direção ao sopé, tendo o perfil 7 mineralogia mista entre 2:1 não-expansiva (mica) e 1:1 (caulinita), com pequena partici pação de gibbsita e de vermiculita.

A participação crescente das micas primárias e secundárias, estas últimas formadas por transformação direta da mica primária, a partir do ombro da vertente em direção ao sopé, foi detectada na fração areia por meio do exame mi cromorfol ógico e na fração argila por DRX. Tal fato e a ocorrência de mica somente após $8 \mathrm{~m}$ de profundidade no topo da vertente, ao se atingir a alteração do substrato rochoso, apoiam a hipótese de mudança de material de origem a partir da meia encosta da vertente.

\section{Pedogênese}

A gênese dos microagregados dos Latossolos (Figuras 3a,b,c,d) parece ser complexa e provavelmente conseqüência de mais de um processo de formação para que se possa explicar este tipo de agregados, tal como sugerem Stoops \& Buol (1985). Nas descriç̧ões micromorfológicas (Quadro 3), ficou evidente o processo de microestruturação geoquímica descrita por Beaudou et al. (1972) e depois por Muller (1977), dando origem aos microagregados a partir da microfissuração contínua da trama porfírica do material argiloso de origem (Figuras 3c e 3d). Agregados zoogenéticos, também mencionados, apresentam características descritas por Eschenbrenner (1986) e Miklós (1993). Outros microagregados não atendem aos requisitos que estes autores apresentam para justificar a origem biológica, ressaltando-se a presença de microagregados com esquel eto pouco triado, com partículas superiores a $100 \mu \mathrm{m}$, e a forma esférica também comum (micronódulos).

O horizonte BA apresenta agregados pol iédricos centimétricos, cuja forma sugere conterem um empacotamento demicroagregados (Figura 3b). Esse empacotamento seria favorecido pela maior atividade biológica nos horizontes mais próximos da superfície e pelo maior número de ciclos de umedecimento com saturação e posterior secamento dessa zona, promovendo defor mações mecânicas que aumentariam o tamanho dos agregados (Moniz \&
Buol, 1982). Por outro lado, no mesmo horizonte, foram descritas zonas de enfraquecimento da estrutura poliédrica, formando microestrias que sugerem a individualização futura do agregado em diversos micronódulos (Quadro 3). Assim, o mecanismo de adensamento do horizonte BA nos Latossolos argilosos estudados parece estar em situação de equilíbrio, não sendo provável que, com o passar do tempo, os agregados aumentem de tamanho e densidade abaixo deste horizonte, pelo menos na posição de topo das vertentes.

A passagem lateral de Bw para Bt no ombro da seqüência parece seguir os seguintes mecanismos: adensamento devido à ação mecânica do fluxo lateral de água (Moniz \& Buol, 1982); mudança das condições para o caminhamento da água feito de forma concentrada nas paredes dos agregados poliédricos, favorecendo o transporte de argilas no perfil (Castro, 1989) e a coalescência dos microagregados pré-existentes (F igura 3 e); argiluviação mais intensa na parte superior do perfil (Quadro 3), com posterior obstrução parcial de porosidade, levando a hidromorfismo temporário que, por sua vez, promove a remoção do fer ro e facilita a argiluviação (Lepsch et al., 1977; Queiroz Neto et al., 1981). Na transição entre A e Bt, ocorre coalescência de cavidades (Figura 3f), o que caracteriza depleção tanto mecânica como química (Castro, 1989), incluindo aí mecanismos localizados provavelmente de degradação de argila em condições de hidromorfismo, processo chamado de ferrólise por Brinkman (1969-1970) e descrito em solos com B textural no Brasil por al guns autores como Almeida et al. (1997).

A partir da meia encosta, o remanejamento de materiais de horizontes inferiores para os superiores por ação de organismos, o denominado "remonte biológico" (E schenbrenner, 1987; Miklós, 1992), seria responsável pela mistura de materiais da cobertura neocenozói ca argil osa com os sedimentos dos siltitos do Ptt aos quais, no local, estão diretamente superpostos e constituem o material de origem dos solos, não tendo havido a formação de B Iatossólico na maior parte deste segmento devertente. Também aqui a argiluviação e os processos de migração de ferro dominam a pedogênese (Figura 4a), sendo evidente a formação do $\mathrm{E}$ às expensas do $\mathrm{Bt}$ (Figura 4b e Quadro 3).

No sopé, a pedogênese ocorre sob hidromorfismo de grau moderado e diretamente sobre os siltitos do $\mathrm{Ptt}$, tendo sido o gradiente textural observado formado pela ação conjunta do coluvionamento (Quadro 3) e os processos de argiluviação e de ferrólise (Figuras 4c e 4d). A ferrólise, nestas condições de drenagem, é muito mais evidente que nas transições entre A e Bt da meia encosta.

$O$ incremento gradativo da saturação por bases (V\%) (Quadro 2) a partir do terço médio até o sopé deve estar relacionado com o aumento gradual da 
(a)

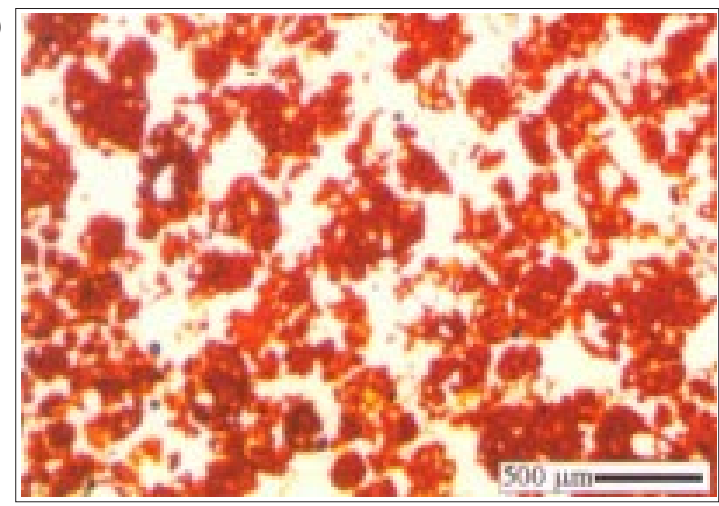

(c)

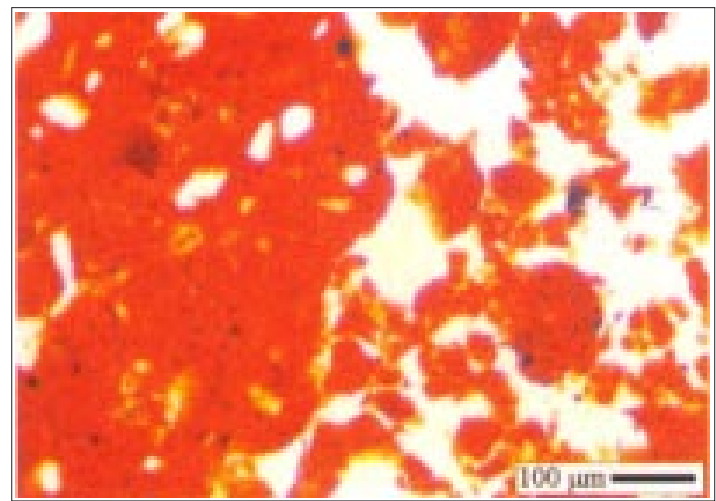

(e)

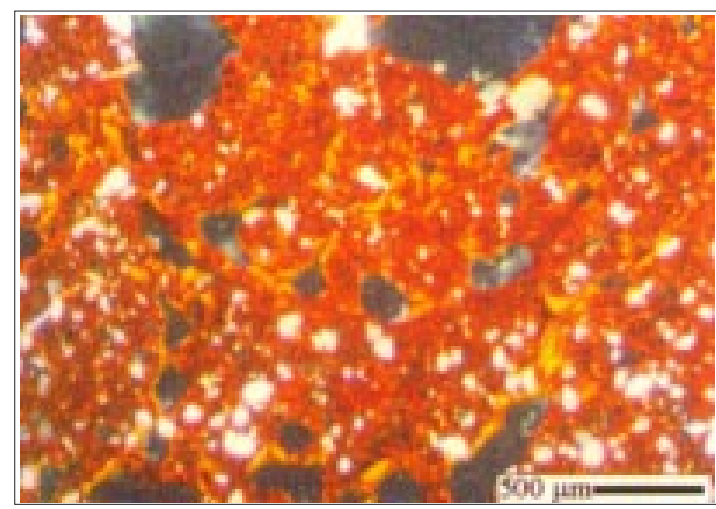

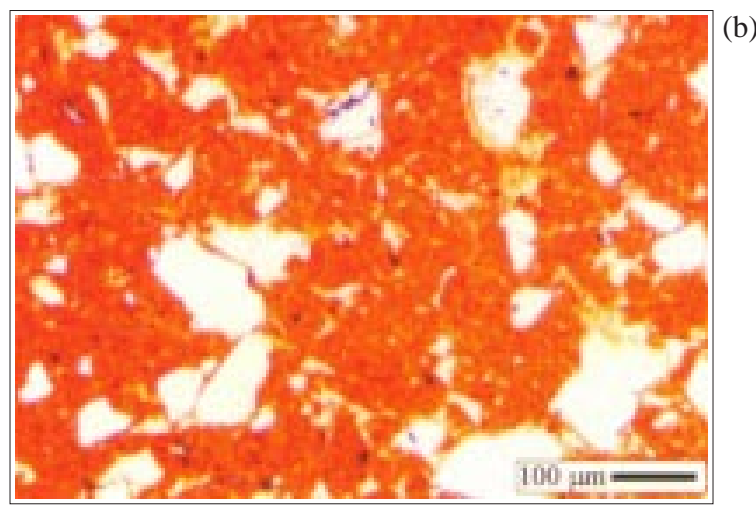

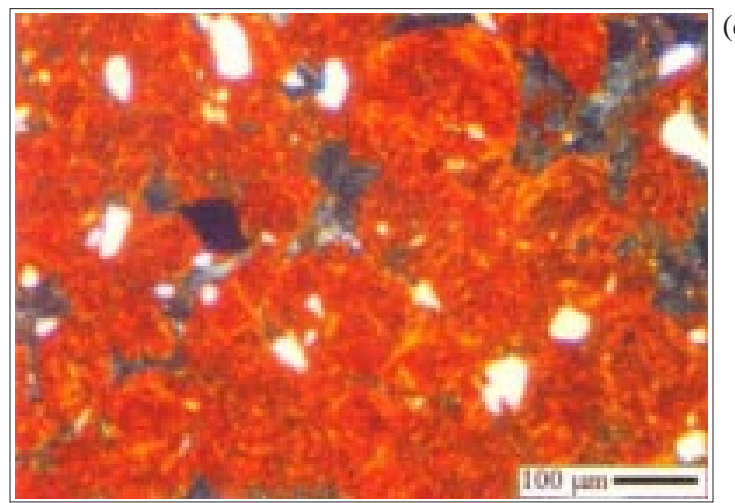

(d)

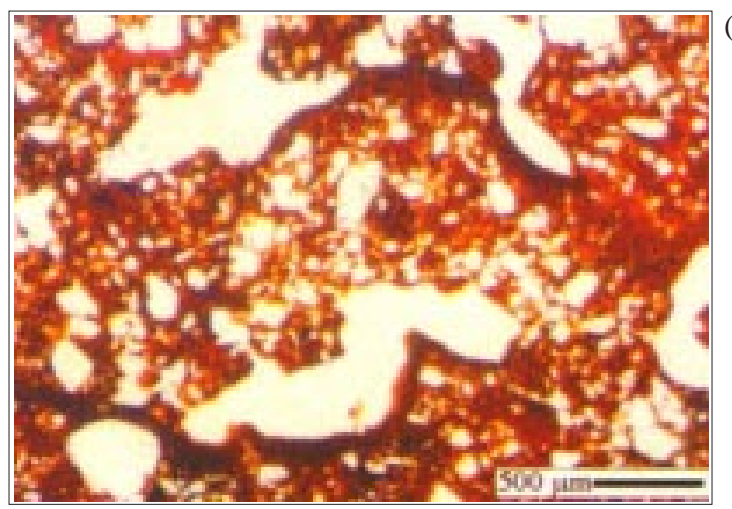

Figura 3. Fotomicrografias dos perfis 1 e 5: (a) horizonte Bw do perfil 1 com trama grânica; (b) horizonte BA $(80-90 \mathrm{~cm})$ do perfil 1 com empacotamento de microagregados (trama apórica granóidica); (c) fragmentação de agregado centimétrico denso em microagregados no horizonte Bw próximo ao 2BC do perfil 1 (600-610 cm); (d) material porfírico do horizonte Bw do perfil $1(600-610 \mathrm{~cm})$ com malha de zonas estriadas onde os microagregados se individualizam preferencialmente (nicóis cruzados); (e) trama porfírica com cavidades do horizonte Bt1 $(103-110 \mathrm{~cm})$ do perfil 5; distribuição dos ferriargilãs mostra coalescência de microagregados por argiluviação; (f) transic ção A/Bt do perfil 5; trama porfírica com coalescência de cavidades cujas paredes inferiores estão revestidas por ferrãs de difusão.

contribuição dos siltitos permianos com níveis carbonáticos da formação Tatuí (Ptt), observados no local, como material de origem dos sol os do sopé. A formação deagregados prismáticos de grau forte com superfícies de compressão no Bt dos solos do sopé deve-se ao el evado conteúdo de argila associado à presença significativa de argilas 2:1, lito-herdadas dos siltitos do Ptt. O menor fluxo lixiviante no sopé propicia a manutenção de valores elevados de saturação por bases no horizonte Btg, assim como val ores de $\mathrm{pH}$ ligeiramente superiores, favorecendo a estabilidade dessa mineral ogia mais ativa. 


\section{Quadro 3. Atributos micromorfológicos dos perfis estudados}

\begin{tabular}{|c|c|c|c|c|}
\hline \multirow{2}{*}{ Atributo } & \multicolumn{4}{|c|}{ Perfil } \\
\hline & $P 1$ e $P 4^{(1)}$ & P5 & P6 & P7 \\
\hline $\begin{array}{l}\text { E strutura } \\
\text { do plasma }\end{array}$ & $\begin{array}{l}\text { I sótico com leve } \\
\text { birrefringência no } \\
\text { horizonte BA passando a } \\
\text { isótico no Bw. Massépico } \\
\text { a partir de 2BC. }\end{array}$ & Vomassépico & $\begin{array}{l}\text { Massépico no E e } \\
\text { vomassépico no Bt }\end{array}$ & $\begin{array}{l}\text { Massépico no } \mathrm{E}, \\
\text { vomaesquel sépico no Bt } \\
\text { e vomassépico a } \\
\text { vomaesquel sépico no Btg }\end{array}$ \\
\hline Trama & $\begin{array}{l}\text { A pórica-granóidica no } \\
\text { BA passando a grânica } \\
\text { ou grânica-granóidica no } \\
\text { Bw. }\end{array}$ & $\begin{array}{l}\text { Porfírica no A, passando } \\
\text { a porfírica com cavidades } \\
\text { e canais no Bt e } \\
\text { localmente granóidica. }\end{array}$ & $\begin{array}{l}\text { Gefúrica com pequenos } \\
\text { domínios porfíricos no } \mathrm{E} \text {. } \\
\text { Porfírica no Bt. }\end{array}$ & $\begin{array}{l}\text { Gefúrica com domínios } \\
\text { porfíricos no E. Porfírica } \\
\text { fissurada no Bt. }\end{array}$ \\
\hline Feições & $\begin{array}{l}\text { Pedotúbulos, cavidades e } \\
\text { canais elipsoidais } \\
\text { indicam bioturbação } \\
\text { intensa em todos os } \\
\text { horizontes. Cutãs de } \\
\text { estresse ocorrem na } \\
\text { borda dos agregados } \\
\text { poliédricos do BA e no } \\
\text { seu interior há uma } \\
\text { tendência micronodular, } \\
\text { marcada por zonas de } \\
\text { maior birrefringência ao } \\
\text { redor dos micronódulos } \\
\text { (microestrias). }\end{array}$ & $\begin{array}{l}\text { Ferriargilãs abundantes } \\
\text { no Bt e ocorrência } \\
\text { comum de pápulas na } \\
\text { transição A-Bt; halos, } \\
\text { ferrãs e descoloração do } \\
\text { plasma são freqüentes no } \\
\text { Bt. Alguns domínios } \\
\text { porfíricos são } \\
\text { microagregados } \\
\text { colaescidos por } \\
\text { ferriargilãs. }\end{array}$ & $\begin{array}{l}\text { Concentrações } \\
\text { plásmicas, com } \\
\text { ferriargilãs e fundo } \\
\text { matricial em degradação, } \\
\text { esparsas na transição E- } \\
\text { Bt (pedorrelíquias do Bt } \\
\text { em E). Ferriargilãs } \\
\text { abundantes, complexos e } \\
\text { microestratificados. } \\
\text { Pápulas e poros } \\
\text { bloqueados por cutãs são } \\
\text { muito freqüentes no topo } \\
\text { do Bt, assim como ferrãs } \\
\text { e a descoloração do } \\
\text { plasma. Muitos nódulos } \\
\text { ferruginosos } \\
\text { incorporados ao fundo } \\
\text { matricial no Bt. }\end{array}$ & $\begin{array}{l}\text { Agregados angulares no } \\
\text { Bt. Feições de } \\
\text { mobilização de ferro } \\
\text { (halos, glébulas e cutãs) } \\
\text { em todo o perfil, sendo } \\
\text { comuns na transição A- } \\
\text { E, onde formam } \\
\text { recobrimentos } \\
\text { horizontais e contínuos, } \\
\text { passando a abundantes } \\
\text { no Btg. Ferriargilãs } \\
\text { comuns nas paredes dos } \\
\text { agregados. Os diferentes } \\
\text { tipos de cutãs aparecem } \\
\text { mesclados nas paredes } \\
\text { dos agregados do Btg. }\end{array}$ \\
\hline Observações & $\begin{array}{l}\text { Grãos de quartzo bem } \\
\text { selecionados e } \\
\text { arredondados. Na } \\
\text { transição Bw-2BC } \\
\text { presença de domínios } \\
\text { porfíricos com } \\
\text { microfissuras em uma } \\
\text { trama granóidica. }\end{array}$ & $\begin{array}{l}\text { Coalescência cavitária } \\
\text { observada na transição } \\
\text { A-Bt. Os grãos são } \\
\text { moderadamente } \\
\text { selecionados e } \\
\text { subarredondados, com } \\
\text { ocorrência de mica } \\
\text { aumentando no 2Bt2. }\end{array}$ & $\begin{array}{l}\text { Grãos pouco sel ecionados } \\
\text { e de arredondamento } \\
\text { variável, com ocorrência } \\
\text { comum de mica e } \\
\text { feldspatos. }\end{array}$ & $\begin{array}{l}\text { Grãos mal selecionados } \\
\text { (de areia muito fina a } \\
\text { média), com mica e } \\
\text { feldspatos comuns no } \\
\text { Btg e raros no Ap e no E. } \\
\text { Nos horizontes } \\
\text { superficiais, a areia fina } \\
\text { tem maior grau de } \\
\text { esfericidade e } \\
\text { arredondamento do que } \\
\text { nos horizontes } \\
\text { subsuperficiais }\end{array}$ \\
\hline
\end{tabular}

(1) Como os perfis 1, 2, 3 e 4 são equivalentes morfol ogicamente, optou-se pela escol ha dos perfis 1 e 4 para a análise micromorfológica dos Latossolos do topo da seqüência. 
(a)

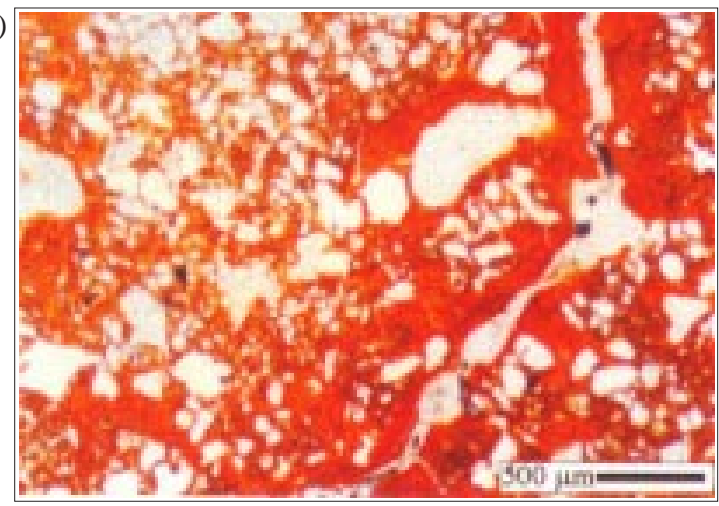

(c)

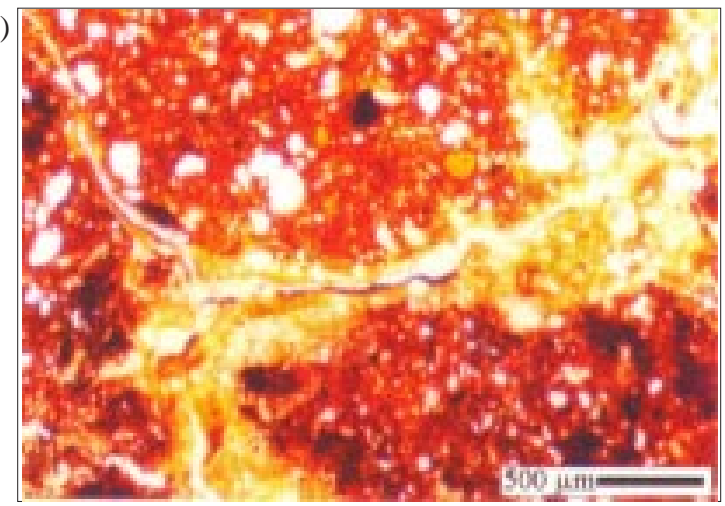

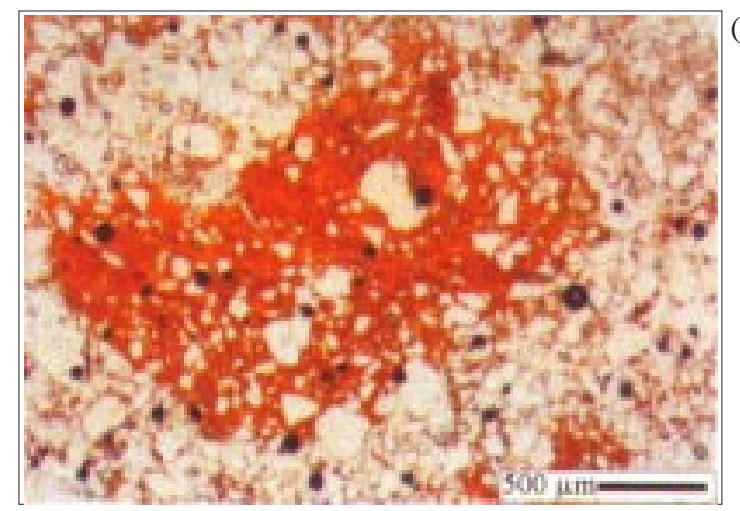

(b)

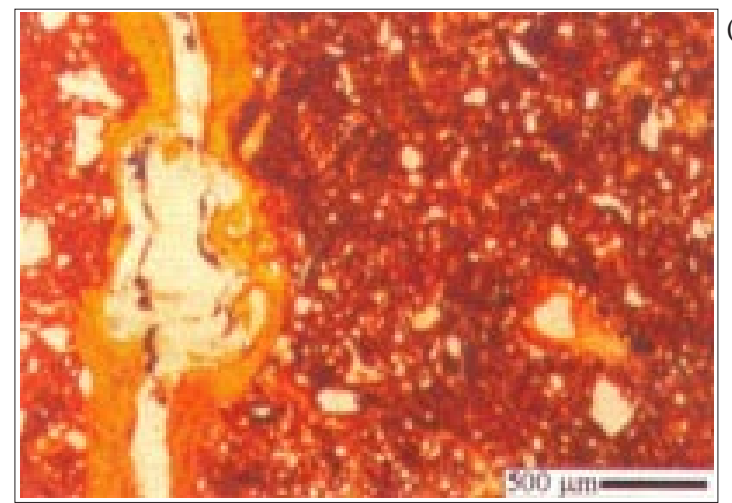

(d)

Figura 4. Fotomicrografias dos perfis 6 e 7; (a) perfil 6, horizonte Bt1 $(64-75 \mathrm{~cm})$ com trama porfírica, matriz mais amarelada (descolorida), presença de ferriargilãs de iluviação e de ferrãs; (b) perfil 6, transição E-Bt $(40-50 \mathrm{~cm})$ com pedorrelíquia de Bt em E ; (c) perfil 7, horizonte Bt1 $(50-60 \mathrm{~cm})$; agregados com tendência angular; cutãs de natureza diversa (difusão, estresse e argiluviação) e abundância de feições de hidromorfismo temporário (halos, ferrãs e nódulos); (e) perfil 7, horizonte Bt2 (75-90 cm) com argilãs de iluviação revestindo um canal.

\section{CONCLUSÕES}

1. A gênese dos microagregados dos Latossolos é complexa e deve ter havido mais de um processo de formação que possa explicá-la. É evidenteo processo de microestruturação, em que, a partir da microfissuração contínua de um material denso argiloso, individualizam-se os microagregados. Agregados formados pela fauna do solo também foram identificados.

2. A passagem lateral de Bw para Bt parece seguir o seguinte modelo: após o ental hamento da superfície cimeira do platô, a dinâmica da água na vertente mudou, propiciando o adensamento do manto latossólico, devido à ação mecânica do fluxo lateral de água, mudança das condições para o caminhamento da água, que o faz de forma concentrada nas paredes dos agregados pol iédricos. I stofavoreceu o transporte de argilas, oque provocou a obstrução gradativa e parcial da porosidade, levando a hidromorfismo temporário, que, por sua vez, promovea remoção do ferro, o que facilita ainda mais a argiluviação; a argiluviação ainda promove a ligação entre mi croagregados, favor ecendo a formação de agregados maiores; na transi ção A/Bt, ocorre coalescência cavitária, evidenciandotantoas perdas mecânicas como as químicas (ferrólise), aumentando o gradiente textural. A partir da meia encosta, o material de origem do sol o deixa de ser o manto latossólico e passa gradativamente para os siltitos da formação Tatuí, não tendo havido, nessa posição, a formação de B latossólico.

3. A passagem de caráter álico no topo para eutrófico no sopé deve-seà contribuição progressiva vertente abaixo dos siltitos carbonáticos da formação Tatuí (Ptt) como material de origem dos solos.

\section{AGRADECIMENTOS}

À FAPESP, pelo auxílio financeiro para a realização deste trabalho; à família Furlan (Usina Furlan), pelas facilidades concedidas para os 
trabal hos de campo; ao Dr. Edvard Elias de Souza Filho (Universidade de Maringá), pel a contribuição nos trabalhos geológicos, e ao IPT-DIGEO, por permitir a utilização do fotomicroscópio.

\section{LITERATURA CITADA}

ALMEIDA, F.F.M. Fundamentos geológicos do relevo paulista. Geologia do estado de São Paulo. São Paulo, Instituto de Geografia e Geologia,1964. p.167-263. (Boletim, 41)

ALMEIDA, J .A.; KLAMT, E. \& KÄMPF, N. Gênese do contraste textural e da degradação do horizonte $B$ de um Podzólico Vermelho-Amarelo da Planície Costeira do Rio Grande do Sul. R. Bras. Ci. Solo, 21:221-233, 1997.

BEAUDOU, A.G.; CHATEZIN, Y.; COLLINET, J . \& SALA, G.H. Notes sur la micromorphologie de certains ferralitiques jaunes de region équatoriels d'Afrique. Cah. ORSTOM, Ser. Pedol., 4:357-370, 1972.

BOULET, R., Análise estrutural da cobertura pedológica e cartografia. In: MONIZ, A.C.; FURLANI, A.M.C.; FURLANI, P. \& FREITAS, S.S. A responsabilidade social da ciência do solo. Campinas, Sociedade Brasileira de Ciência do Solo, 1988. p.79-90.

BREWER, R. Fabric and mineral analysis of soils. New York, Robert E. Krieger, 1976. 482p.

BREWER, R. \& SLEEMAN, J .R. Soil structure and fabric. Adelaide, CSIRO, Division of Soils. 1988. 173p.

BRINKMAN, R. Ferrolysis, a hydromorphic soil forming process. Geoderma, 3:199-206, 1969/1970.

CAMARGO, M.N.; KLAMT, E. \& KAUFTMAN, J .H. Classificação de sol os usada em levantamentos pedológicos no Brasil. B. Inf. SBCS, 12:11-33, 1987.

CAMARGO, O.A.; MONIZ, A.C.; J ORGE, J .A. \& VALADARES, J .M.A.S. Métodos de análise química, mineralógica e física de sol os do Instituto Agronômico de Campinas. Campinas, Instituto Agronômico de Campinas, 1986. 94p (Boletim Técnico, 106)

CASTRO, S.S. Sistemas detransformação pedológica em Marília, SP: B latossólicos e B texturais. São Paulo, Universidade de São Paulo, 1989. 274p. (Tese de Doutorado)

CASTRO, S.S. I mpregnação de amostras de sol o para confecção de lâmina delgada. B. Inf. SBCS, 10:44, 1985.

CHAUVEL, G.; BOCQUIER, G. \& PEDRO, G. La stabilité et la transformation de la microstructure des sols rouges ferralitiques de Casamance(Senegal). Analysemicroscopique et donnés experimentales. In: INTERNATIONAL WORK. MEETING SOIL MICROMORPHOLOGY, 5., Granada, 1979. Proceedings. Granada, Universidad de Granada, 1978. p.779-813.

COMISSÃO DE SOLOS - CSS. Levantamento de reconhecimento dos sol os do estado de São Paulo. Rio deJ aneiro, Ministério da Agricultura, CNEPA, SNPA, 1960. 634p. (Boletim, 12)

EUA. Soil Survey Staff. Soil Taxonomy: A basic system of soil classification for making and interpreting soil surveys. Washington, 1975. v.5. 330p. (Agric. Handb., 436)
ESCHENBRENNER, V. Contribution des termites a la microagregation des sols tropicaux. Cah. Orstom, Ser. Pedol., 22:397-408, 1986.

ESCHENBRENNER, V. Les glébules des sols de côte d'I voire. Dijon, Université de Bourgogne, 2v. 780p. 1987. (Tese de Doutorado)

FEDOROFF, N. \& ESWARAN, H. Micromorphology of Ultisols. In: SOIL MICROMORPHOLOGY AND SOIL CLASSIFICATION. Proceedings of a symposium sponsored by Division S-5 and S-9 of the Soil Science Society of America. Madison, Soil Science Society of American, 1985. p.145-164.

FONTES, M.P.F. Vermiculita ou esmectita com hidróxi nas entrecamadas: proposição de nomenclatura. B. Inf. SBCS,15:24-28, 1990.

INSTITUTO DE PESQUISAS TECNOLÓGICAS - IPT. Mapa geológico do estado de São Paulo. Escala 1:1.000.000. Divisão de Minas e Geologia Aplicada do Instituto de Pesquisas Tecnológicas do estado de São Paulo. São Paulo, 1981.

JACKSON, M.L. Soil chemical analysis. Advanced course. Madison, 1969. 894p.

KARATHANASIS, A.D.; ADAMS, F. \& HAJ EK, B.F. Stability relationships in kaolinite, gibbsite and Al-hidroxyinterlayered vermiculite soil systems. Soil Sci. Soc. Am. J., 47:1247-1251, 1983.

LEPSCH, I.F . \& BUOL, S.W.. Investigations in an oxissol-ultissol topossequence in São Paulo State, Brazil. Soil Sci. Soc. Am. Proc., 38:491-496, 1976.

LEPSCH, I.F.; BUOL, S.W. \& DANIELS, R.B. Soil landscape relationships in the occidental plateau of São Paulo, Brazil: II Soil morphology, genesis and classification. Soil Sci. Soc. Am. J ., 41:109-115, 1977.

MIKLÓS, A.A.W. Byodinamique d'une couverture pedologique dans la région de Botucatu, Brésil. Paris, Université Paris VI. 2v. 438p. 1992. (Tese de Doutorado)

MIKLÓS, A.A.W. Funcionamento biodinâmico da paisagem. Ci. \& Amb., 4:75-83, 1993.

MONIZ, A.C. \& BUOL, S.W. Formation of an oxisol-ultisol transition in São Paulo, Brazil: I-Double-water flow model of soil development. Soil Sci. Soc. Am. J ., 46:1234-1237, 1982.

MONIZ, A.C. Evolução de conceitos no estudo da gênese de solos. R. Bras. Ci. Solo, 20:349-362, 1996.

MULLER, J.P. Microstructuration des structichrons rouges ferralitiques, à l'amont des modelés convexes (CentreCameroun). Aspecs morphologiques. Cah. Orstom, Ser. Pédol., 15:239-258, 1977.

OLIVEIRA, J .B.; ALFONSI, R.R. \& PEDRO J r., M.J . Regimes hídricos e térmicos dos solos do estado de São Paulo. In: CONGRESSO BRASILEIRO DE CIÊNCIA DO SOLO, 15. Campinas, 1976. Anais. Campinas, Sociedade Brasileira de Ciência do Solo, 1976. p.359-362.

PENTEADO, M.M. Geomorfologia do Setor Centro Ocidental da Depressão Periférica Paulista. Rio Claro, Universidade de São Paulo, 1968. 86p. (Tese de Doutorado) 
QUEIROZNETO, J.P.; CASTRO, S.S.; FERNANDES BARROS, O.N.; MANFREDINI, S.; PELLERIN, J .; RUELLAN, A. \& TOLEDO, G.S. Um estudo de dinâmica de solos: formação e transformação de perfis com horizonte $B$ textural. In: CONGRESSO BRASILEIRO DE CIÊNCIA DO SOLO, Salvador, 1980. Campinas, Sociedade Brasileira de Ciência do Solo, 1981. p.67.

RAIJ , B. van; QUAGGIO, J .A.; CANTARELLA, H.; FERREIRA, M.E.; LOPES, A.S. \& BATAGLIA, O.A. Análise química do solo para fins de fertilidade. Campinas, Fundação Cargill, 1987. 165p.

STOOPS, G. Le profil dálteration au Bas-Congo (Kinshasa). As description et as genèse. Pedologie, 17:60-105, 1967.

STOOPS, G. Micromorphology of the oxichorizon. In: BULLOCK, P. \& MURPHY, C.P., eds. Soil micromorphology. Soil genesis. Berkhamsted, Herts. AB Academic, 1983.v.2. p.419-440.
STOOPS, G. \& J ONGERIUS, A. Proposal for a micromorphological classification of soil materials. I. A classification of the related distribuion of fine and coarse particles. Geoderma, 13:189-199, 1975.

STOOPS, G. \& BUOL S.W. Micromorphology of Oxisols. In: DOUGLAS, L.A. \& THOMPSON, M.L., eds. Soil micromorphology and soil classification. Madison, Soil Science Society of American, 1985. p.105-119.

VIDAL TORRADO, P. \& LEPSCH, I.F. Morfogênese dos sol os de uma toposseqüência com transição $B$ latossólico $\times B$ textural sobre migmatitos em Mococa (SP). R. Bras. Ci. Solo, 17:109119, 1993.

VIDAL-TORRADO, P.; LEPSCH, I .F . \& SOUZA FILHO. Relações solos-estratigrafia-geomorfologia em uma área sobre sedimentos pal eozóicos em Piracicaba (SP). R. Bras. Ci. Solo, 1999. (no prelo) 